\title{
Diabetic eNOS knockout mice develop distinct macro- and microvascular complications
}

\author{
Sumathy Mohan ${ }^{1}$, Robert L Reddick', Nicolas Musi², Diane A Horn', Bo Yan³, Thomas J Prihoda ${ }^{3}$, \\ Mohan Natarajan ${ }^{3}$ and Sherry L Abboud-Werner ${ }^{1}$
}

Functional consequences of impaired endothelial nitric oxide synthase (eNOS) activity causing organ-specific abnormalities on a diabetic setting are not completely understood. In this study, we extensively characterized a diabetic mouse model (lepr ${ }^{\mathrm{db} / \mathrm{db}}$ ) in which eNOS expression is genetically disrupted (eNOS ${ }^{-1-}$ ). The eNOS ${ }^{-1-} /$ lepr ${ }^{\mathrm{db} / \mathrm{db}}$ double-knockout (DKO) mice developed obesity, hyperglycemia, hyperinsulinemia and hypertension. Analysis of tissues from DKO mice showed large islets in the pancreas and fat droplets in hepatocytes. Interestingly, the aorta was normal and atherogenic lesions were not observed. Abnormalities in the aorta including poor re-endothelialization and increased medial wall thickness were evident only in response to deliberate injury. In contrast, significant glomerular capillary damage in the kidney was identified, with DKO mice demonstrating a robust diabetic nephropathy similar to human disease. The vascular and renal impairments in DKO mice were pronounced despite lower fasting plasma glucose levels compared to lepr $\mathrm{db}^{\mathrm{db}}$ mice, indicating that eNOS is a critical determinant of hyperglycemia-induced organ-specific complications and their severity in diabetes. Results provide the first evidence that absence of eNOS in diabetes has a greater deleterious effect on the renal microvasculature than on the larger aortic vessel. The DKO model may suggest novel therapeutic strategies to prevent both vascular and renal complications of diabetes.

Laboratory Investigation (2008) 88, 515-528; doi:10.1038/labinvest.2008.23; published online 7 April 2008

KEYWORDS: diabetes; endothelial dysfunction; eNOS; micro- and macrovasculature; nephropathy and vasculopathy

Macro- and microangiopathy including accelerated atherosclerosis and nephropathy are the most common complications of diabetes. Reduced bioavailabilty of nitric oxide (NO), due to impaired nitric oxide synthase (NOS) activity, is implicated in the generation of these abnormalities. ${ }^{1-3} \mathrm{NO}$ is formed from L-Arginine by three isoforms of NOS with stoichiometric production of L-citrulline. Among the three isoforms, endothelial NOS (eNOS) is constitutively expressed predominantly in the macrovascular endothelium and along the renal microvascular tree. Basal release of eNOS-driven NO by endothelial cells contributes to the maintenance of normal vasodilatory tone and thromboresistance. Under conditions of hyperglycemia and associated increase in advanced glycation end products, there is excessive generation of superoxide, which interacts with NO resulting in the formation of peroxynitrites. The peroxynitrites oxidize tetrahydrobiopterin, an important cofactor involved in normal eNOS activity. The deficiency of tetrahydrobiopterin causes
eNOS uncoupling, which results in increased generation of superoxide rather than NO. Overall, superoxide generation is amplified in macrovessels in diabetes with concomitant reduction in the level of bioavailable NO.

Nitric oxide also acts as a potent modulator of renal function and controls both afferent and efferent vascular tone, glomerular ultrafiltration coefficient ${ }^{4,5}$ and medullary blood flow. ${ }^{6}$ However, the precise contribution of eNOS/NO in promoting kidney lesions under diabetic conditions remains controversial. ${ }^{7}$ Reduced bioavailability of NO under high-glucose conditions, as demonstrated in in vitro studies, contradicts in vivo studies where an enhanced renal $\mathrm{NO}$ production and/or its activity have been shown under hyperglycemic conditions. ${ }^{7-9}$ This raises the question whether or not hyperglycemia is directly responsible for these complications or they appear as secondary effect due to impaired NO regulation. Differential mechanisms have been postulated with the use of in vitro cultures of vascular endothelial

\footnotetext{
${ }^{1}$ Department of Pathology, The University of Texas Health Science Center, San Antonio, TX, USA; ${ }^{2}$ Department of Medicine, The University of Texas Health Science Center, San Antonio, TX, USA and ${ }^{3}$ Department of Otolaryngology Head \& Neck Surgery, The University of Texas Health Science Center, San Antonio, TX, USA Correspondence: Dr Sumathy Mohan, PhD, Assistant Professor, Department of Pathology, University of Texas Health Science Center, 7703 Floyd Curl Drive, San Antonio, TX 78229, USA. E-mail: mohan@uthscsa.edu

Received 06 November 2007; revised 11 January 2008; accepted 18 January 2008
} 
cells. Although some reports demonstrated the downregulation of eNOS expression and activity under conditions of high glucose, thus implicating the direct mitigation of eNOS expression by high glucose, ${ }^{10}$ many reports have demonstrated that the prolonged exposure to high glucose increased eNOS expression, nitrite release with the concomitant production of superoxide, which may ultimately result in reduced bioavailability of NO. ${ }^{11,12}$ The attenuated NO bioavailability may impair endothelial cell function. The high glucose-induced endothelial dysfunction therefore, could play a major role in the development of diabetic vascular and renal complications. ${ }^{13,14}$

To precisely understand the contribution of eNOS in vascular complications of diabetes, in the present study, we generated a unique double-knockout (DKO) mouse model with genetically disrupted eNOS isoform systemically on a diabetic background. These mice inherited characteristics such as obesity, elevated fasting blood glucose levels and high insulin resistance from the lepr ${ }^{\mathrm{db} / \mathrm{db}}$ parental mice and elevated blood pressure with reduced vascular repair characteristics from eNOS ${ }^{-1-}$ parents. We anticipated that DKO mice would exhibit large-vessel atherogenesis due to depletion of eNOS. Unexpectedly, abnormalities in these vessels were evident only in response to deliberate vessel injury, whereas significant alterations were observed in glomerular capillary bed of the kidney with DKO mice demonstrating a robust nephropathy similar to human disease.

Our findings show, for the first time, that eNOS mediates differential effects in macro- and microvessels and is essential for regulating endothelial repair in large vessels in response to injury. Systemic depletion of eNOS on a diabetic background allows the study of both vascular and renal pathology in the same animal. Moreover, DKO mice can readily be used to assess the efficacy of drug therapy to target multiple-organ pathologies.

\section{MATERIALS AND METHODS Breeding and Genotyping}

Female $\mathrm{eNOS}^{-1-}$ mice (strain B6.129P2-Nos3 ${ }^{\text {tmlUnc }}$ ) and hemizygous $\left(\mathrm{m}+1+\right.$ lepr $\left.^{\mathrm{db}}\right)$ breeding male (strain BKS. $\mathrm{Cg}-\mathrm{m}+/+$ Lepr $^{\mathrm{db}}$ ) were obtained from Jackson Laboratories (ME, USA). Homozygous $\mathrm{eNOS}^{-1-}$ mice on a diabetic background were obtained after several back crossings of these parental strains. Animals were provided with recommended breeding diet and the cages with pregnant females were housed in special breeding rooms. All procedures were performed in accordance with National Institutes of Health guidelines with approved protocol by the UTHSCSA Institutional Animal Care and Use Committee.

The tail snips obtained from litters at the time of weaning (about 3 weeks after birth) were used to identify their genotype using a PCR/restriction-length polymorphism assay. Purified DNA from tail snips were subjected to PCR amplification using the following primers and conditions recommended by Jackson Laboratories. The primers used for eNOS genotyping include (i) $5^{\prime}$-CTCCAACTTAGTG CAGGTCT- $3^{\prime}$, (ii) $5^{\prime}$-ATGGTTGCCTTCACACGCTT-3' and (iii) $5^{\prime}$-CTTCCTCGTGCTTTACGGTA- $3^{\prime}$. The primers used for db typing were (i) 5'-AGAACGGACACTCTTTGA AGTCTC- $3^{\prime}$ and (ii) $5^{\prime}$-CATTCAAACCATAGTTTAGGT TTGTGT- $3^{\prime}$. The PCR product of db genotype was further digested with Rsa-1 restriction enzyme and the digested samples were examined using $12 \%$ polyacrylamide gels. The gels stained with ethidium bromide were then scanned and the results were recorded for every litter as a pedigree chart. Hemizygous $(+/-)$ animals with both eNOS and db genotypes obtained from initial breeding experiments were used for cross-breeding once again to obtain homozygous eNOS knockouts with hemizygous $\mathrm{lepr}^{+/ \mathrm{m}}$ genotype. Crossbreeding of the homozygous eNOS knockouts bearing hemizygous lepr ${ }^{+/ \mathrm{m}}$ genotype resulted in litters that were both eNOS knockouts and diabetics (lepr ${ }^{\mathrm{db} / \mathrm{db}}$ ) referred to as DKO in this manuscript. A minimum of 10 rounds of back crossings were carried out to obtain genetic homogeneity. Phenotypes based on coat color and body habitus agreed with PCR genotyping in all cases.

Control group includes predominantly hemizygous mice (littermates) that were generated during the breeding process and also wild-type (C57Bl/KsJ background) mice purchased from Jackson Laboratories. Single $\mathrm{eNOS}^{-1-}$ mice and lepr ${ }^{\mathrm{db} / \mathrm{db}}$ mice that resulted as littermates were also included as additional controls. Clinical parameters including blood pressure were analyzed in 14- to 16-week-old mice.

\section{Systolic and Diastolic Blood Pressure Measurements}

Systolic and diastolic blood pressure measurements were performed using Visitech blood pressure measurement system available at the In vivo Research Services of Jackson Laboratory, Sacramento, CA, USA. Mice were subjected to 10 min per day of acclimation to the system under restrainers with tail cuffs for 4 days. On the fifth day, after few runs of acclimation, actual systolic and diastolic blood pressure measurements were performed.

\section{Clinical Parameters}

Body weights were measured weekly and prior to sacrifice the animals. After $8-9 \mathrm{~h}$ of starvation, blood samples were collected by cardiac puncture while the animals were under sedation. Serum insulin was measured by enzyme-linked immunosorbent assay (Crystal Chem, Downers Grove, IL, USA) and glucose was determined by the oxidase method using a Beckmann instrument.

Twenty-four-hour urine samples were collected from individually caged mice using Nalgene ${ }^{\mathrm{R}}$ metabolic cages (Nalgene Nunc International, Rochester, NY, USA). Urine albumin and creatinine concentrations were measured by enzyme-linked immunosorbent assay (Exocell, Philadelphia, PA, USA) using a DCA2000 analyzer. 


\section{Histopathological Analysis}

Immediately after the animals were euthanized, vital organs including liver, spleen, pancreas, kidneys, lungs and hearts were excised. Portion of each organ was either frozen or fixed in $3.7 \%$ paraformaldehyde. Organs were collected from a total of three controls, four eNOS ${ }^{-1-}$, four lepr ${ }^{\mathrm{db} / \mathrm{db}}$ and six DKO mice. Hematoxylin and eosin-stained sections $(5 \mu \mathrm{m}$ thickness) of these organs were examined to determine whether or not abnormalities were present.

\section{Vascular Injury Procedures}

Wounding of the abdominal aorta in five control, five lepr ${ }^{\mathrm{db} / \mathrm{db}}$, six eNOS ${ }^{-/-}$and six DKO mice was performed. For vascular injury procedures, 12 -week-old mice were used. In lepr ${ }^{\mathrm{db} / \mathrm{db}}$ and DKO mice older than 12 weeks, their obesity compromised the ability to perform surgical procedures. The mice were anesthetized with 3\% isoflurane using a liquid vaporizer. The abdomen was opened and the abdominal aorta from below the renal arteries to the bifurcation was freed from the surrounding adventitial adipose tissue by gentle dissection using forceps. Injury was induced for a $1-\mathrm{cm}$ segment by gently squeezing the aorta between round-tipped forceps as previously reported. ${ }^{15}$

A gentle squeeze with forceps led to a simple endothelial denudation, that is removal of endothelium in the artery. The uninjured region of the artery served as a control for each mouse. All the animals had excellent survival after surgery. The abdomen was closed and the animals were sacrifice 15 days post-surgery. A group of mice were killed after $1 \mathrm{~h}$ of surgery to confirm endothelial denudation. While the animals were under heavy sedation, they were perfused with $4 \%$ paraformaldehyde ( $0.1 \mathrm{M}$ phosphate buffer, $\mathrm{pH} 7.2)$ by intracardiac infusion. The aortae were placed in fresh paraformaldehyde until processed for further study. The fixed aortae were processed for paraffin embedding. Three to five sequential sections $(5-\mu \mathrm{m}$ thick) were stained with Masson's trichrome. Endothelial-cell coverage of the luminal surface at the injured area was assessed by examining the sections at a final magnification of $\times 400$. Histomorphometric analysis was performed using a computerized live-image analysis system and Bioquant software (Bioquant Image Analysis Corporation, Nashville, TN, USA). The number of nuclei stained in the intimal layer at the injured segment of the aortae was counted. The number of endothelial cells per $\mathrm{mm}$ intima was calculated by measuring the length of the injured intimal layer using Bioquant software. The extent of re-endothelialization was expressed in terms of percent coverage considering coverage in control group as $100 \%$. The average medial wall thickness of the injured region was also determined by tracing the inner and outer edges of the vessel wall using Bioquant software and measuring the linear distance from the inner elastic lamina to the external elastic lamina. The Bioquant software system provides options to have width lines drawn at $10-\mu \mathrm{m}$ intervals. The perpendicularity of the width lines can be adjusted to allow precise width measurements along the entire segment of vessel. In each vessel section, the wall thickness of the injured region was measured in three serial sections for each animal and the values were averaged. The histogram presented represents the mean wall thickness calculated for all animals in each genotype investigated in this study.

\section{Quantitative Evaluation of Renal Pathology Renal histology}

Kidneys were removed and tissue from each kidney was processed for paraffin, immunofluorescent and electron microscopic studies. A total of 24 mice was examined at 16 weeks of age: $\mathrm{m}+/+\operatorname{lepr}^{\mathrm{db}} \quad(n=6) ;$ lepr $^{\mathrm{db} / \mathrm{db}} \quad(n=6)$; $\mathrm{eNOS}^{-1-}(n=6)$; DKO $(n=6)$. Kidney slices were fixed in $10 \%$ formalin, dehydrated through graded ethanol and xylene and embedded in paraffin. Four-micrometer thick sections were stained with periodic acid-Schiff (PAS), methanamine silver or picrosirius red. For the latter stain, sections were placed in $0.2 \%$ phosphomolybdic acid for $2 \mathrm{~min}$, rinsed in water and then incubated with $0.1 \%$ Sirius red F3B (Sigma-Aldrich, St Louis, MO, USA) in saturated picric acid for $1 \mathrm{~h}$. Previous studies analyzing eNOS-deficient kidneys indicated that picrosirus red was more useful than Masson trichrome for identifying collagen fibrils within the interstitium. ${ }^{16}$ To localize endothelial cells, indirect immunoperoxidase staining was performed using PECAM-1 antibody (platelet-endothelial cell-adhesion molecule, Santa Cruz sc-1506; 1:500 dilution) as previously described. ${ }^{16}$ Sections were incubated using the avidin-biotin-horseradish peroxidase technique (Elite Vectastain ABC kit; Vector Laboratories, Burlingame, CA, USA) and staining was visualized using 3,3'-diaminobenzidine. Proliferating cells were identified by incubating sections with an antibody to the proliferating cell nuclear antigen (PCNA, Santa Cruz sc-7907; 1:100) followed by reagents in the Biocare rabbit-Alkaline phosphatase polymer detection kit (Biocare, Concord, CA, USA). To identify apoptotic cells, the terminal deoxynucleotidyl transferase-mediated dUTP-biotin nick end-labeling (TUNEL) method was used. ${ }^{17}$ To analyze tissue macrophages or glomerular fibrin deposition, samples were embedded in OCT compound (Miles Inc., Elkhart, IN, USA) and snap-frozen in isopentane. Cryostat sections $(7-\mu \mathrm{m})$ were immunostained with macrophage marker CD68 (FA-11) (Serotech, Oxford, UK), 1:100, according to established methods. Fibrin was detected by incubating the sections with FITC-conjugated rabbit anti-human fibrinogen, which crossreacts with mouse (DakoCytomation, Glostrup, Denmark), at a dilution of 1:10 for $1 \mathrm{~h}$, followed by washing and mounting the slides. To ensure consistent staining quality, slides were stained in a single session with the same conditions and reagents.

For electron microscopy, tissue blocks $\left(1 \mathrm{~mm}^{3}\right)$ were fixed in $4 \%$ formaldehyde/ $1 \%$ glutaraldehyde, embedded in epoxy resin, and ultrathin sections were stained with uranyl acetate and lead citrate. Cortical tissue was screened to ensure adequate sampling of various glomerular morphologies observed 
by light microscopy. Digital images and glomerular basement membrane (GBM) measurements were made using an Advanced Microscopy Techniques digital camera system (Danvers, MA, USA) and measuring package on a Joel 1230 electron microscope. At least 15 different segments of GBM per mouse from three mice were measured in each group.

\section{Quantification of renal morphology}

Histomorphometric measurements of glomerular volume, cellularity and matrix fraction, tubular injury and interstitial volume were determined using the Bioquant system and software (Bioquant Image Analysis Corporation). All quantifications were performed in a blinded manner. On PASstained sections, 25 glomerular profiles per mouse were examined. Glomeruli in focal cortical scars were excluded from analysis. The glomerular volume was assessed by tracing along the outline of the glomerular tuft. The mesangial matrix was determined by measuring the nucleus-free PASpositive area in the mesangium and the matrix fraction was calculated as the percentage of mesangial/glomerular area. Glomerular cellularity was evaluated in uninjured glomeruli by counting the number of nuclei per glomerular cross-section (gcs). The average glomerular volume, matrix fraction and cellularity were calculated for each group of mice and expressed as mean \pm S.E. Fibrin deposition was evaluated in 50 gcs per mouse and the percent of glomeruli showing positive staining involving more than two-thirds of the total glomerular area was calculated. In coronal sections of the kidney, all glomeruli (100-200 glomeruli) were examined for glomerular injury defined as any of the following: mesangiolysis, microaneruysms, nodular lesions and total sclerosis. The percentage of glomerular injury (injury index) was calculated as the number of injured glomeruli divided by total glomeruli. The number of macrophages and apoptotic (TUNEL-positive) cells in each gcs were enumerated. The percent of tubular injury within the entire coronal section was assessed by tracing tubules showing acute (defined as dilatation, intratubular casts and necrosis) and chronic (defined as thickened basement membranes and atrophy) injury and determining the ratio of injured tubular/total tubulointerstitial area. Tubules were analyzed for apoptotic and proliferative indices by counting the number of TUNELor PCNA-positive cells. Interstitial macrophages were enumerated and interstitial volume was calculated as the percent of picrosirius red-positive staining/total tubulointerstitial area. The vascular adventitia and focal scars were excluded from interstitial macrophage and volume measurements.

\section{Statistical Methods}

One-way analysis of variance was used to compare means for the four groups. Pair-wise multiple comparisons were done following this analysis to compare each of the three other group's means with the double-knockout mean. Significance level for those is reported at $P<0.05, P<0.01$ and $P<0.001$ as indicated in the tables. Residuals of the analysis of variance were checked for having a bell-shaped curve and homogenous variances in each of the four groups. When this was not true, the standard log transformation was used to help assure that the assumptions of the analysis of variance were met to provide a valid analysis.

\section{RESULTS}

\section{Genotyping of the Double-Knockout Mice, General Appearance and Body Weight}

Purified DNA isolated from tail snips of 3-week-old pups was screened for DKO genotype that is $\mathrm{eNOS}^{-1-}$ and lepr $\mathrm{rb}^{\mathrm{db}} \mathrm{db}$ genotype by PCR and restriction digestion as described in the Materials and Methods section. A representative profile of a double-knockout genotype is presented in Figure 1. Probability of obtaining more DKO genotype occurred when the breeding pairs were of homozygous eNOS ${ }^{-1-}$ and hemizygous on $\mathrm{db}$ locus $\left(\mathrm{lepr}^{+/ \mathrm{m}}\right)$. The DKO mice were obese, with a mystic coat color and sterile like lepr ${ }^{\mathrm{db} / \mathrm{db}}$. The lepr $^{\mathrm{db} / \mathrm{db}}$ and the DKO mice exhibited significant increase in body weights compared to control and $\mathrm{eNOS}^{-1-}$ mice. The average lifespan of these mice was approximately 9 months to 1 year without insulin treatment.

\section{Double-Knockout Mice are Diabetic and Insulin Resistant}

As shown in Table 1, the fasting plasma glucose levels of the lepr ${ }^{\mathrm{db} / \mathrm{db}}$ and DKO mice were very high thus confirming their diabetic status. However, compared to the lepr ${ }^{\mathrm{db} / \mathrm{db}}$ mice, the DKO mice exhibited significantly reduced plasma glucose levels. Also, both lepr $^{\mathrm{db} / \mathrm{db}}$ and the DKO mice exhibited significantly elevated plasma insulin levels compared to the levels of $\mathrm{eNOS}^{-1-}$ and control mice indicating that they are insulin resistant. The DKO mice showed extremely high circulating insulin levels compared to the lepr ${ }^{\mathrm{db} / \mathrm{db}}$ mice.

In addition, serum cholesterol and triglyceride levels were determined to assess whether these profiles correlate with other diabetic characteristics of the DKO mice. At 14-16 week of age, no significant difference in the triglyceride levels was observed between the DKO mice and the other genotypes. However, the plasma cholesterol of DKO mice was significantly higher compared to control, lepr ${ }^{\mathrm{db} / \mathrm{db}}$ or eNOS ${ }^{-/-}$ mice.

\section{Double-Knockout Mice are Hypertensive}

The average blood pressure measurements of $\mathrm{eNOS}^{-1-}$ and DKO mice after acclimation to the system for 4 days showed moderately high systolic blood pressure. The eNOS ${ }^{-1-}$ mice exhibited high systolic blood pressure consistent with an earlier report. ${ }^{18}$ As shown in Table 1 , the DKO mice had increased systolic blood pressure comparable to the level of $\mathrm{eNOS}^{-1-}$ mice. In contrast, the systolic blood pressure of lepr ${ }^{\mathrm{db} / \mathrm{db}}$ mice was very close to that observed in wild-type mice. No difference was noticed in the pulse levels in all these genotypes (Table 1). 
Genotype profile

\begin{tabular}{|l|l|l|l|}
\hline Strain & Wild type & Hemizygous & Homozygous \\
\hline $\begin{array}{l}\mathrm{db} \\
\mathrm{PCR}+\mathrm{Rsal} \\
\text { digestion }\end{array}$ & $135 \mathrm{bp}-$ uncut & $\begin{array}{l}135 \mathrm{bp}-\text { uncut } \\
108 \mathrm{bp} \text { and } 27 \mathrm{bp}- \\
\text { cut }\end{array}$ & $\begin{array}{l}108 \mathrm{bp} \text { and } 27 \mathrm{bp}- \\
\text { cut }\end{array}$ \\
\hline eNOS PCR product & $370 \mathrm{bp}$ PCR product & $\begin{array}{l}370 \mathrm{bp} \text { and } 450 \mathrm{bp} \\
\text { PCR product }\end{array}$ & 450 PCR product \\
\hline
\end{tabular}

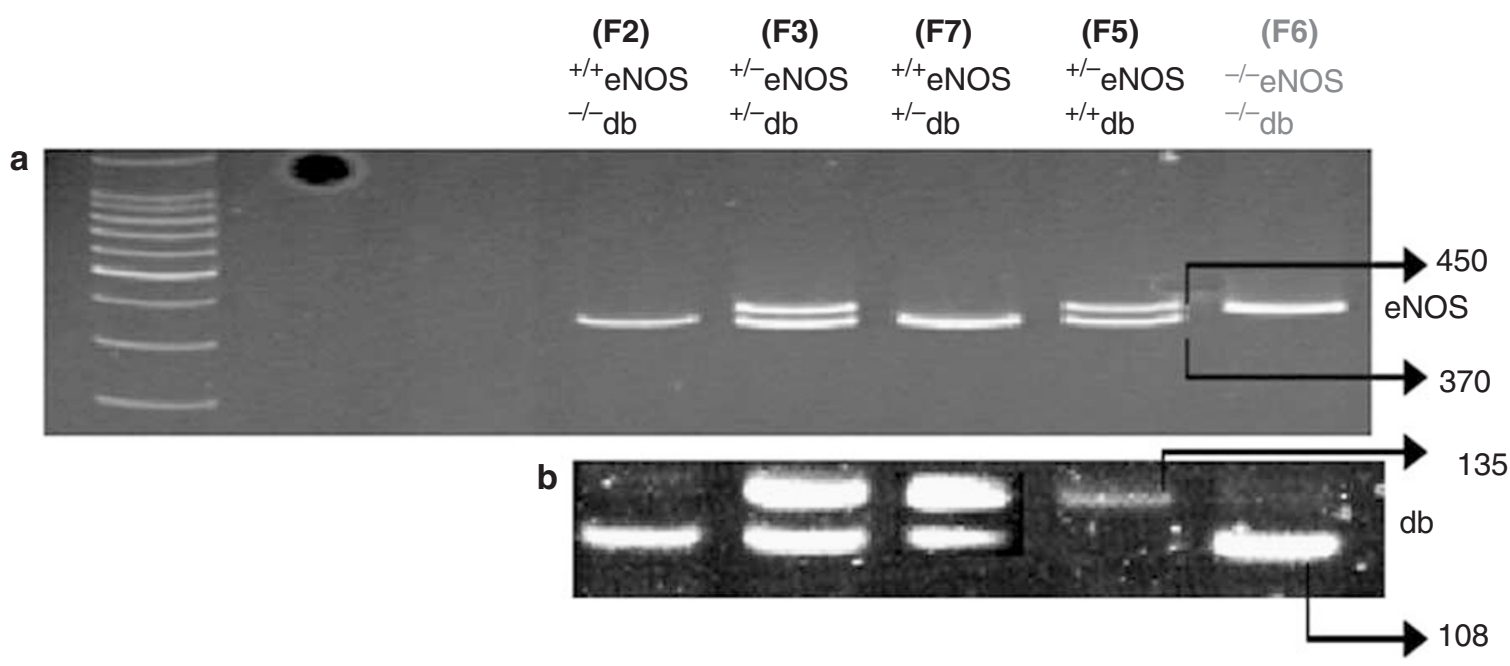

Figure 1 Genotypic analysis of DKO mice. The expected sizes of PCR products of wild-type, heterozygous and homozygous genotypes for eNOS and $\mathrm{db} / \mathrm{db}$ loci are shown in the top panel. The bottom panel represents an acrylamide gel stained with ethidium bromide demonstrating tail DNA profile of various combinations of genotypes obtained in the cross-breeding experiments using female eNOS ${ }^{-1-}$ mice (strain B6.129P2-Nos $3^{\text {tmlUnc }}$ ) and heterozygous lepr ${ }^{\mathrm{db}}$ breeding male (strain BKS.Cg-m $+/+$ Lepr $^{\mathrm{db}}$ ). Lanes labeled F2, 3, 5-7 indicate littermates with different genotypes. F6 is a double-knockout genotype. (a) eNOS genotypes and (b) lepr ${ }^{\mathrm{db} / \mathrm{db}}$ genotypes.

\section{Albumin/Creatinine Ratio is Elevated in DKO Mice}

Albumin/creatinine ratio is a precise clinical marker of progressive diabetic nephropathy. In 24-h urine collections from the DKO mice, urinary albumin/creatinine ratio was significantly increased compared to either control, lepr ${ }^{\mathrm{db} / \mathrm{db}}$ or $\mathrm{eNOS}^{-1-}$ mice. As shown in Table 2, the 24-h urine output in DKO mice was significantly higher compared to all the other genotypes including the lepr ${ }^{\mathrm{db} / \mathrm{db}}$. The significant increase in urine output indicates that the DKO mice exhibit polyuria. Also, to determine the status of renal hypertrophy, the kidneys were weighed. Kidney-to-total body weight ratios were not determined due to obese nature of the lepr ${ }^{\mathrm{db} / \mathrm{db}}$ and the DKO mice, unlike the lean hemizygous control and eNOS ${ }^{-/-}$ mice. The total weight of both the right and the left kidney of the DKO mice was significantly higher than that of the control and eNOS ${ }^{-1-}$ mice. No significant difference in the kidney weight was noticed between DKO and lepr ${ }^{\mathrm{db} / \mathrm{db}}$ mice.

\section{Histological Variations in the Vital Organs of Double-Knockout Mice}

Hematoxylin and eosin-stained sections of spleen, heart and lung of the DKO mice including mice with other genotypes examined in this study were normal. However, vital organs including pancreas, liver and kidneys of the DKO mice exhibited varying abnormalities. In the pancreas, both DKO mice and the lepr ${ }^{\mathrm{db} / \mathrm{db}}$ mice had large islets. However, enlargement of islets was more prominent in DKO mice compared to lepr ${ }^{\mathrm{db} / \mathrm{db}}$ mice (Figure 2). The $\mathrm{eNOS}^{-1-}$ mice exhibited small islets similar to control mice. No inflammatory cells were present in islets of any of four different genotypes. Liver sections of DKO mice showed macro- and microvesicular fat droplets in the hepatocytes (Figure 2). Microvesicular fat droplets were also identified in the lepr ${ }^{\mathrm{db} / \mathrm{db}}$ mice. Livers from $\mathrm{eNOS}^{-1-}$ mice were similar to control mice or showed occasional fatty infiltration. The morphologic abnormalities observed in the aorta and kidneys of DKO mice are described in the following sections.

\section{Vascular Histology and Remodeling Response to Arterial Injury in DKO Mice}

To determine the effect of eNOS deficiency on large-vessel pathology in the setting of diabetes, aortas were dissected from 8- to 18-week-old mice. DKO mice showed no evidence of early or established atherogenic lesions. We then 
Table 1 Physiological parameters

\begin{tabular}{|c|c|c|c|c|}
\hline \multicolumn{5}{|c|}{ Genotypes } \\
\hline Characteristics & $\begin{array}{l}\text { Control, wild-type } \\
\text { or hemizygous }\end{array}$ & lepr ${ }^{\mathrm{db} / \mathrm{db}}$ (diabetic) & $\begin{array}{l}\text { eNOS } \\
\text { eNOS null }\end{array}$ & $\begin{array}{l}\text { DKO (double } \\
\text { knockout) }\end{array}$ \\
\hline Number of mice & $N=8$ & $n=11$ & $n=10$ & $n=8$ \\
\hline Body weight (g) & $25.50 \pm 2.30^{\star * *}$ & $48.88 \pm 4.20^{*}$ & $21.02 \pm 3.58^{\star * *}$ & $56.55 \pm 5.65$ \\
\hline Plasma insulin(pg/ml) & $336.07 \pm 153.00^{* * *}$ & $2068.84 \pm 3227.70^{* * *}$ & $266.58 \pm 56.40^{* * *}$ & $10062.40 \pm 7853.80$ \\
\hline Cholesterol (mg/dl) & $97.25 \pm 17.84^{* * *}$ & $138.00 \pm 26.80^{* * *}$ & $90.98 \pm 34.71^{* * *}$ & $294.25 \pm 104.61$ \\
\hline Triglyceride (mg/dl) & $121.00 \pm 37.64^{\mathrm{a}}$ & $130.22 \pm 58.00^{\mathrm{a}}$ & $113.12 \pm 58.28^{a}$ & $161.50 \pm 65.37$ \\
\hline Systolic blood pressure (mm Hg) & $113.30 \pm 3.80^{\star \star}$ & $112.00 \pm 13.00^{\star *}$ & $144.33 \pm 17.20^{\mathrm{a}}$ & $147.00 \pm 6.10$ \\
\hline Pulse & $567.67 \pm 74.10^{\mathrm{a}}$ & $517.00 \pm 43.71^{\mathrm{a}}$ & $498.00 \pm 83.40^{\mathrm{a}}$ & $479.33 \pm 44.40$ \\
\hline
\end{tabular}

${ }^{\star} P<0.05 ;{ }^{*} P<0.01 ;{ }^{* *} P<0.001$ compared to double-knockout mice.

${ }^{\mathrm{a}}$ Nonsignificant.

Table 2 Renal analysis

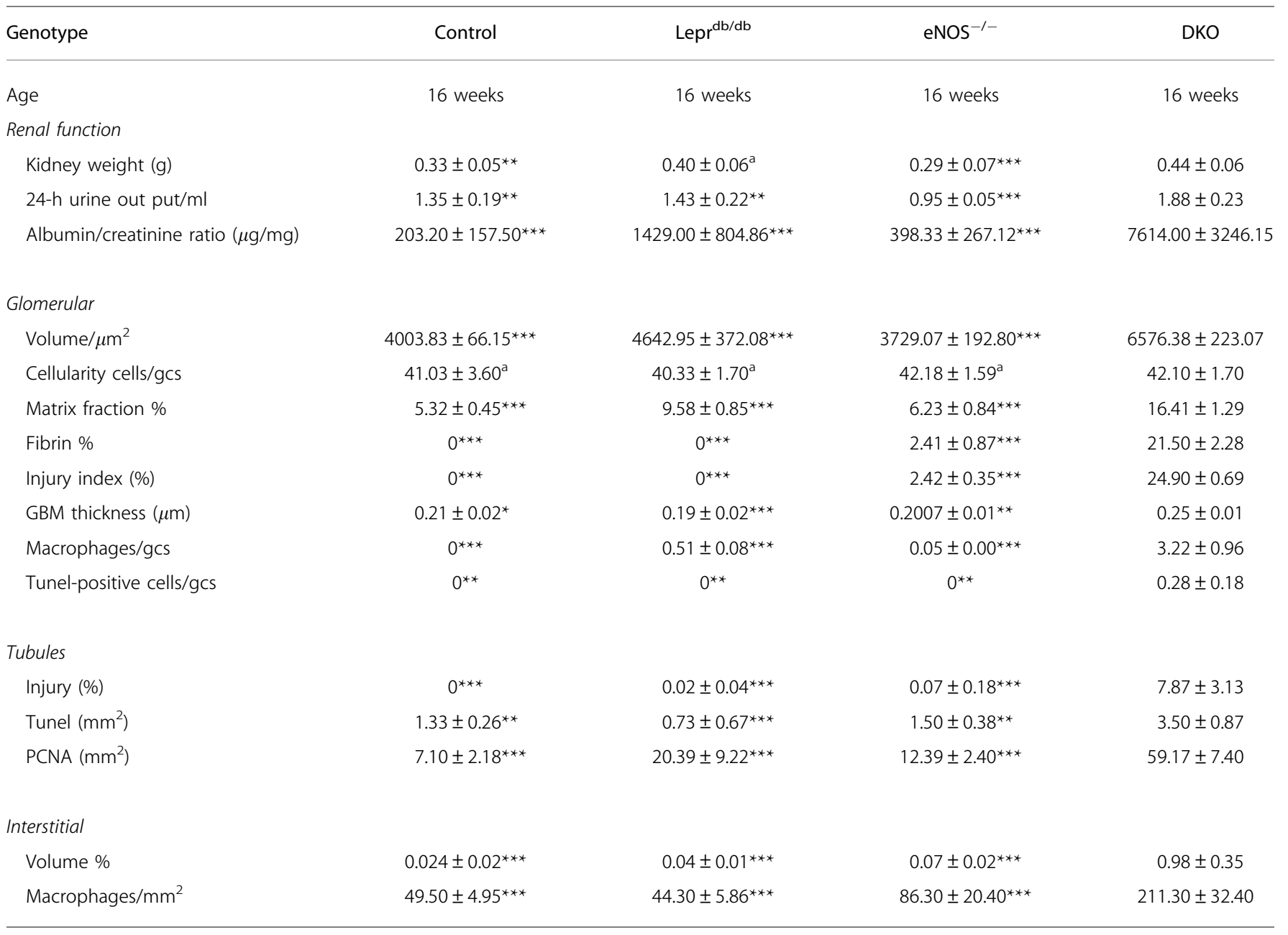

Data are mean \pm S.D. Control, lepr ${ }^{\mathrm{db} / \mathrm{db}}$ and $\mathrm{eNOS}^{-/-}$are compared with DKO.

${ }^{\star} P<0.05 ;{ }^{* *} P<0.01 ;{ }^{* *} P<0.001$.

${ }^{\mathrm{a}}$ Nonsignificant. 


\section{Pancreas}

Control

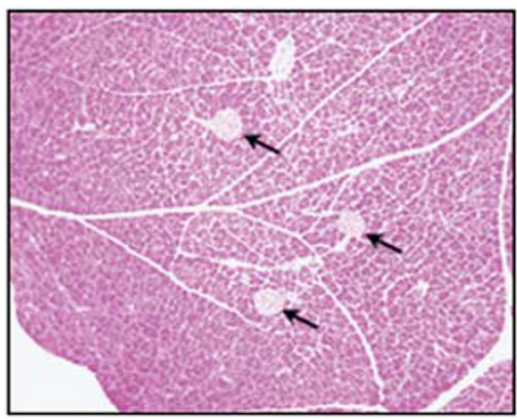

eNOS $^{-1-}$

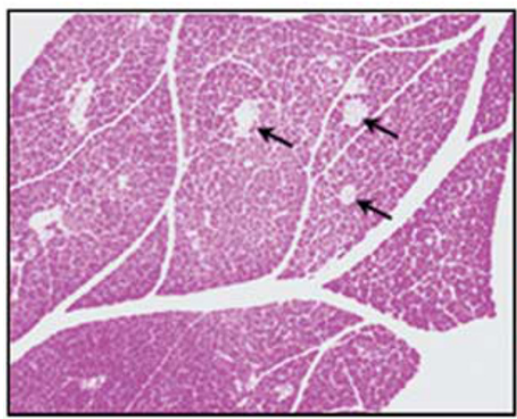

leprdb/db

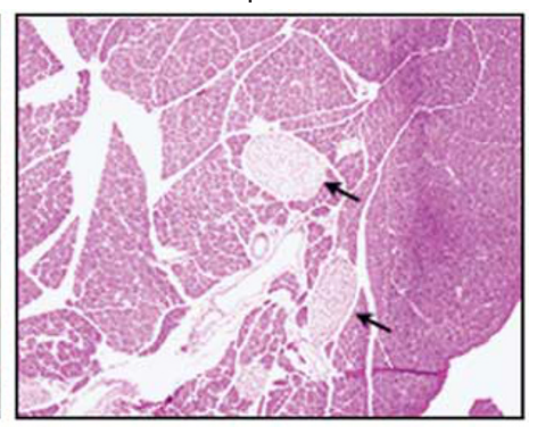

DKO

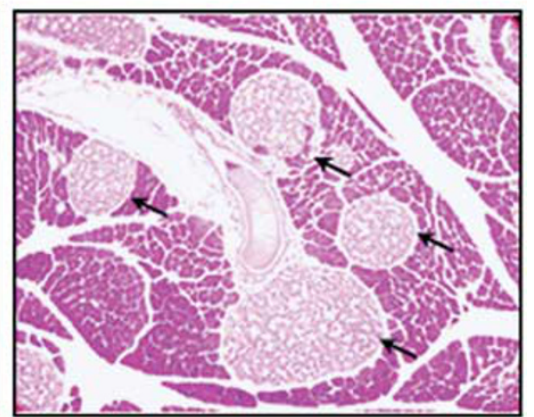

Liver
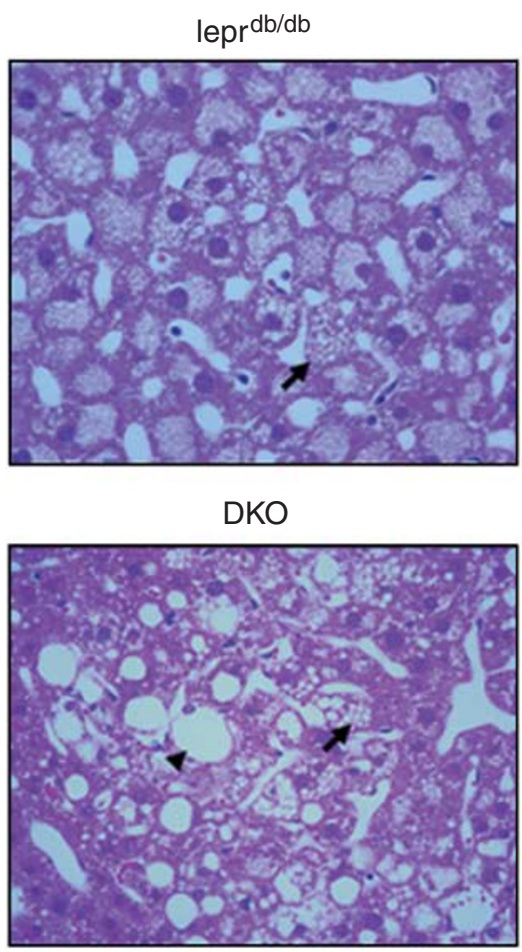

Figure 2 Hematoxylin and eosin-stained sections of pancreas and liver. The DKO mice show moderately large and prominent islets compared to control and $\mathrm{eNOS}^{-1-}$ mice. The lepr ${ }^{\mathrm{db} / \mathrm{db}}$ mice show moderately enlarged islets that are larger than the control but slightly smaller than DKO mice. Arrows indicate islets. Original magnification: $\times 400$. The lepr ${ }^{\mathrm{db} / \mathrm{db}}$ liver shows predominantly a microvesicular pattern (arrow) in contrast to the DKO liver where both micro- (arrow) and macrovesicular (arrowhead) lipid inclusions are present. Original magnification: $\times 600$.

determined the contribution of eNOS in the response mechanisms to external aortic injury under hyperglycemic conditions. The average wall thickness of the injured regions of the abdominal aorta was determined after 15 days of surgery. In addition, the number of endothelial cells along the luminal surface of the injured artery was counted and cells/ $\mathrm{mm}$ of injured intima was determined. The degree of re-endothelialization was expressed as percent coverage considering endothelialization in control mice as $100 \%$. The injured regions of the arteries were identified by the presence of rare pyknotic smooth muscle cells in the aortic media, thickening of adventitial layer by collection of inflammatory cells and from the slight irregularities in the pattern of the elastica. The vascular wall thickness in the injured region was significantly increased in both $\mathrm{eNOS}^{-1-}$ mice $(47.61 \pm 6.59 \mu \mathrm{m})$ and DKO mice $(73.89 \pm 5.13 \mu \mathrm{m}) \mathrm{com}$ pared to the control $(23.6 \pm 4.5 \mu \mathrm{m})$ and lepr ${ }^{\mathrm{db} / \mathrm{db}}$ mice $(25.78 \pm 3.6 \mu \mathrm{m}$; Figure 3$)$. The wall thickness of DKO mice was even higher than that of eNOS ${ }^{-1-}$ mice. Morphometric analysis (Figure 4) of Masson's trichrome-stained sections of vascular segments showed that the endothelial cells along the luminal surface of the injured aorta were significantly decreased in the denuded vascular surface of DKO mice compared to control and lepr ${ }^{\mathrm{d} / \mathrm{db}}$ mice. No significant difference was noted in the degree of endothelial cell coverage between $\mathrm{eNOS}^{-1-}$ mice and the DKO mice. Considering the extent of coverage in control mice as $100 \%$, the lepr ${ }^{\mathrm{db} / \mathrm{db}}$, eNOS ${ }^{-1-}$ and DKO mice exhibited $65.33 \pm 2.89,57.0 \pm 12.5$ and $40.67 \pm 7.57 \%$ re-endothelialization, respectively.

\section{DKO Mice Exhibit a Spectrum of Renal Lesions} Glomerular morphology

Compared to control, lepr ${ }^{\mathrm{db} / \mathrm{db}}$ and $\mathrm{eNOS}^{-1-}$ mice, DKO mice showed significant glomerular injury including mesangiolysis, microaneurysms, increased mesangial matrix expansion with nodular lesions (nodular glomerulosclerosis) and globally sclerotic glomeruli (diffuse glomerulosclerosis) (Figure $5 \mathrm{a}-\mathrm{j}, \mathrm{n}$ ). These alterations increased glomerular volume in DKO mice and were not observed in control or lepr ${ }^{\mathrm{db} / \mathrm{db}}$ mice (Table 2). In eNOS ${ }^{-1-}$ mice, glomeruli were predominantly normal (Figure $5 \mathrm{c}$ ), although occasional mesangiolysis and globally sclerotic glomeruli were identified. Some globally sclerotic glomeruli in $\mathrm{eNOS}^{-1-}$ and DKO mice showed wrinkled and collapsed basement membranes (Figure 5j). The cellularity of uninjured DKO glomeruli was comparable to that of controls. The mesangium was more prominent in DKO compared to lepr ${ }^{\mathrm{db} / \mathrm{db}}$ mice, and some glomeruli showed nodular matrix expansion comprised of 

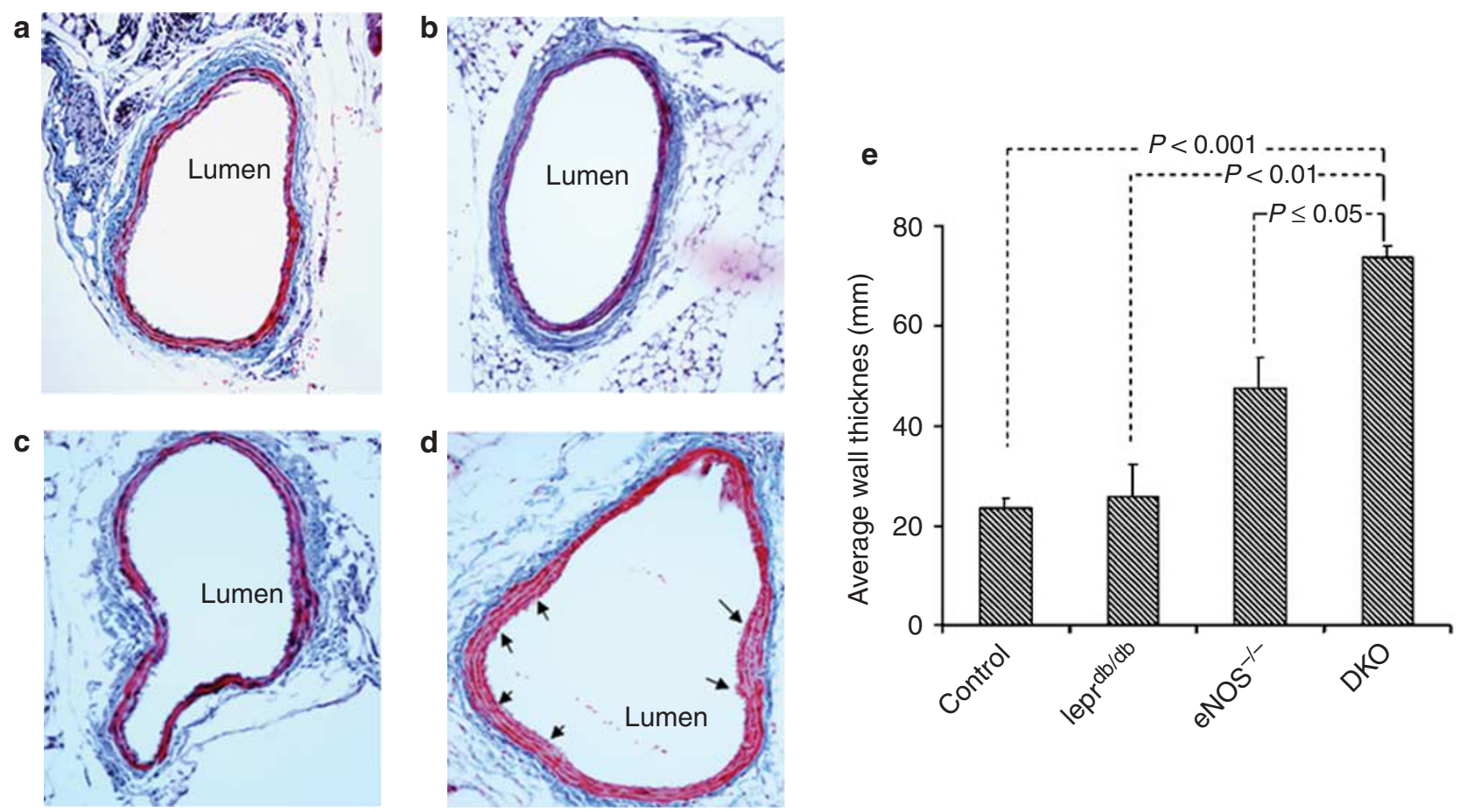

Figure 3 The remodeled abdominal aorta of DKO mice after arterial injury showing increased wall thickness. Masson's trichrome-stained abdominal aortic section from control (a), lepr ${ }^{\mathrm{db} / \mathrm{db}}(\mathbf{b})$, eNOS-/- (c), and DKO (d) mice. Original magnification: $\times 200$. Arrows in (d) show remodeled area with increased wall thickness at the region of injury. (e) Average medial wall thickness directly measured from cross-sections of control, lepr ${ }^{\mathrm{db} / \mathrm{db}}$, eNOS ${ }^{-/-}$ and DKO mice shows significantly increased wall thickness ( $P$-values are shown) in DKO mice compared to the other genotypes.

a

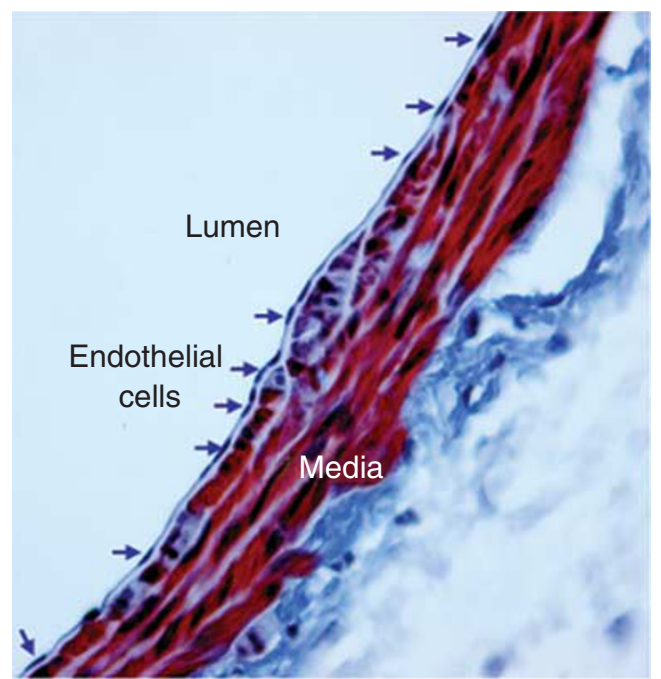

b

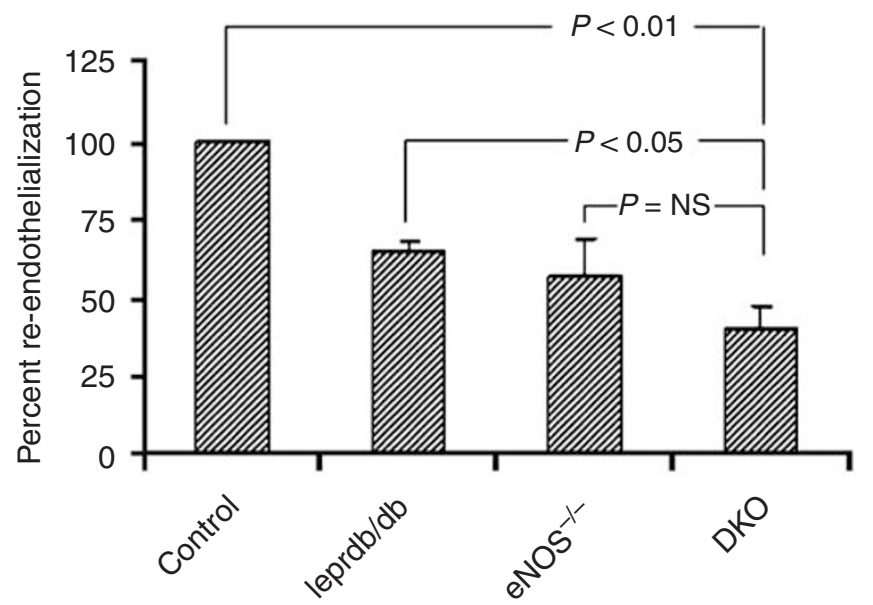

Figure 4 Masson's trichrome-stained section of luminal endothelium 15 days after arterial injury. Identification of endothelial cells. (a) Regrowing endothelial cells (shown by arrows) present at luminal surface of abdominal aorta of DKO mouse 15 days after injury. Original magnification: $\times 400$. (b) Histogram showing percent re-endothelialization of $\mathrm{lepr}^{\mathrm{db} / \mathrm{db}}$, eNOS ${ }^{-1-}$ and DKO mice compared to control (considering endothelialization as $100 \%$ ). The DKO mice show significantly less endothelialization ( $P$-values are shown) compared to control and lepr ${ }^{\mathrm{db} / \mathrm{db}}$ mice. No significant differences were noted between eNOS ${ }^{-1-}$ and DKO mice.

acellular PAS-positive material that resembled KimmelstielWilson-like nodular lesions (K-W nodules) (Table 2, Figure $5 \mathrm{~g})$. Nodular glomerulosclerosis was also identified on methanamine silver stains (Figure 5f, inset). In occasional DKO glomeruli, mesangiolysis was accompanied by nuclear fragmentation or intraluminal fibrin. Adhesions to Bowman's capsule or subendothelial hyaline resembling fibrin caps were observed in some segments (Figure 5h). Occasional glomeruli 

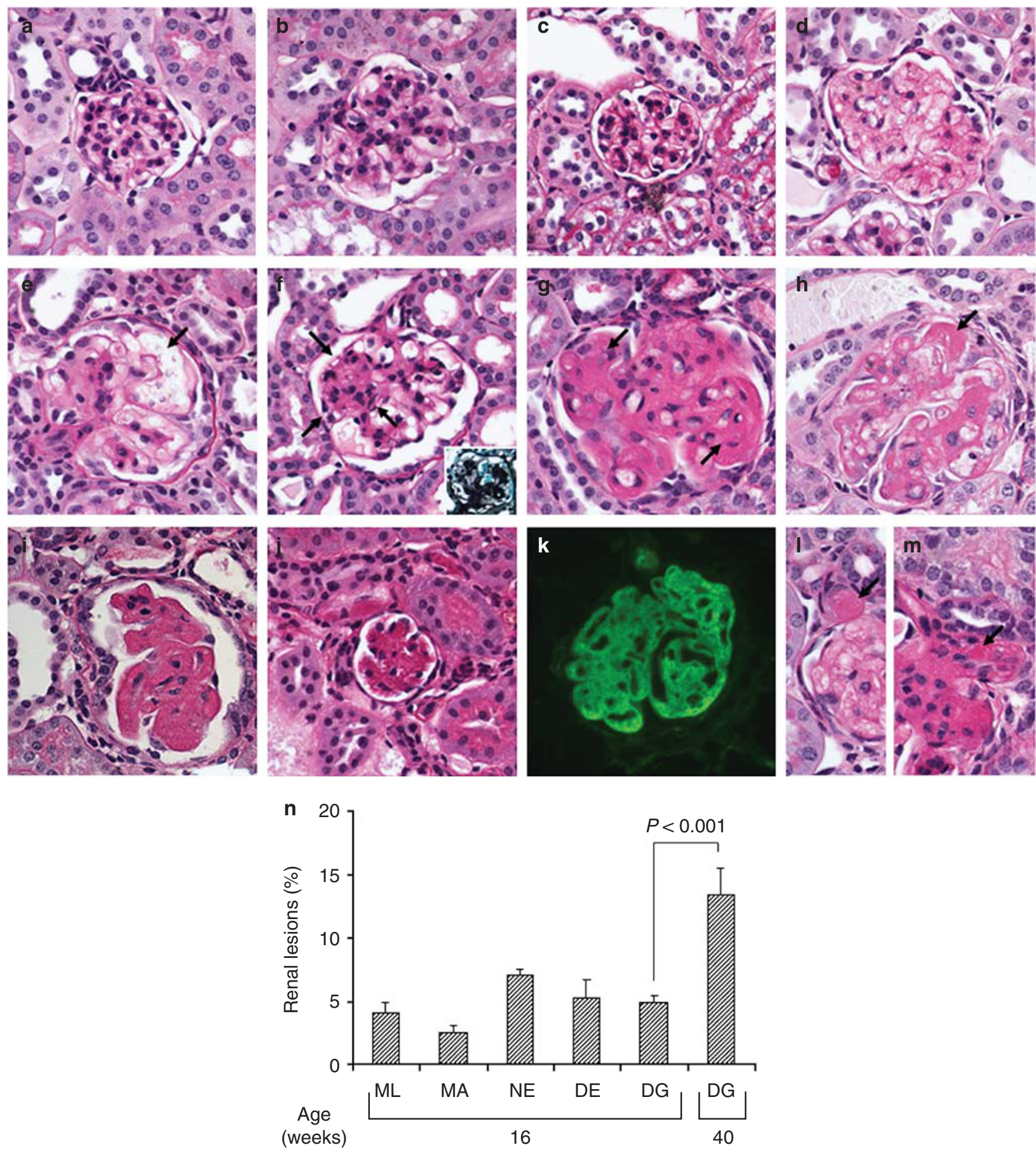

Figure 5 Comparative glomerular morphology in mice at 16 weeks. (a) Normocellular glomerulus in wt/wt mouse. (b) Glomerulus with mild mesangial expansion in lepr ${ }^{\mathrm{db} / \mathrm{db}}$ mouse. (c) Normocellular glomerulus in eNOS ${ }^{-1-}$ mouse. (d-m) Pathologic changes in DKO mice showing (d) mesangiolysis (ML); (e) microaneurysm (MA) (arrow); (f) nodular mesangial expansion (arrows) involving $<50 \%$ of the tuft (NE) and methenamine silver-stained nodules (inset); (g) nodular lesions with acellular PAS-positive material (arrows) involving $>50 \%$ of the tuft (DE); (h) hyaline deposition forming fibrin cap lesion (arrow); (i) diffuse glomerulosclerosis (DG); (j) obsolescent glomerulus with wrinkled basement membranes; (k) fibrin deposition by immunofluorescence; (I) arteriole with fibrin thrombus (arrow); (m) arteriolar hyalinosis at vascular pole of glomerulus (arrow). (n) Quantification of renal lesions in DKO mice with DG analyzed at 16 and 40 weeks of age. Original magnification: $\times 400$ (A-J, L, M: PAS stain; F, inset: methenamine silver stain). 
with mesangiolysis or nodular lesions also showed microaneurysms. Importantly, glomerular injury with nodular lesions was observed as early as 8 weeks in DKO kidneys. By immunofluorescent staining, fibrin deposition was detected in some injured glomeruli in DKO mice (Figure 5k) $(21.50 \% \pm 2.28)$ and in occasional $\mathrm{eNOS}^{-1-}$ glomeruli $(2.41 \% \pm 0.87)$, whereas fibrin was negative in lepr $^{\mathrm{db} / \mathrm{db}}$ and control mice. Rare fibrin thrombi were identified in arterioles of DKO mice (Figure 5l). Both lepr ${ }^{\mathrm{db} / \mathrm{db}}$ and $\mathrm{eNOS}^{-1-}$ as well as DKO mice showed occasional arteriolar hyalinosis at the vascular pole of glomeruli, although hyalinization was more pronounced in DKO mice (Figure $5 \mathrm{~m}$ ). Compared to 16 weeks, DKO mice at 40 weeks showed a 2.8 -fold increase in totally sclerotic glomeruli, indicating progression of glomerular disease with age (Figure $5 n$ ).

\section{Glomerular ultrastructure}

Electron microscopic examination demonstrated no ultrastructural abnormalities in eNOS ${ }^{-1-}$ glomeruli except for a rare glomerulus with mesangiolysis. Compared to $\mathrm{eNOS}^{-1-}$ and lepr ${ }^{\mathrm{db} / \mathrm{db}}$ mice, DKO mice showed increased mesangial expansion (Figure $6 \mathrm{c} v s$ a and b). Morphometric analysis also showed a significant increase in the GBM thickness in DKO mice compared to control, lepr ${ }^{\mathrm{db} / \mathrm{db}}$ and $\mathrm{eNOS}^{-1-}$ mice (Table 2). In DKO mice, occasional segments showed microaneurysm formation due to disruption of anchoring of the GBM to the mesangium (Figure 6d). Some glomeruli showed mesangiolysis characterized by accumulation of electron-lucent material in the mesangium and dissociation of the mesangial matrix. This was accompanied by injured endothelial-cell morphology as demonstrated by swollen endothelial cells, endothelial-cell denudation from the basement membrane, accumulation of subendothelial electronlucent material (insudation) and intracapillary fibrin, platelets and leukocytes (Figure 6e). These features are similar to the glomerular injury in human thrombotic microangiopathy. Occasional DKO glomeruli also showed accentuation of the lobular architecture due to early nodular mesangial matrix expansion (Figure 6f). In all groups of mice, antigenantibody immune complex deposits were not observed.
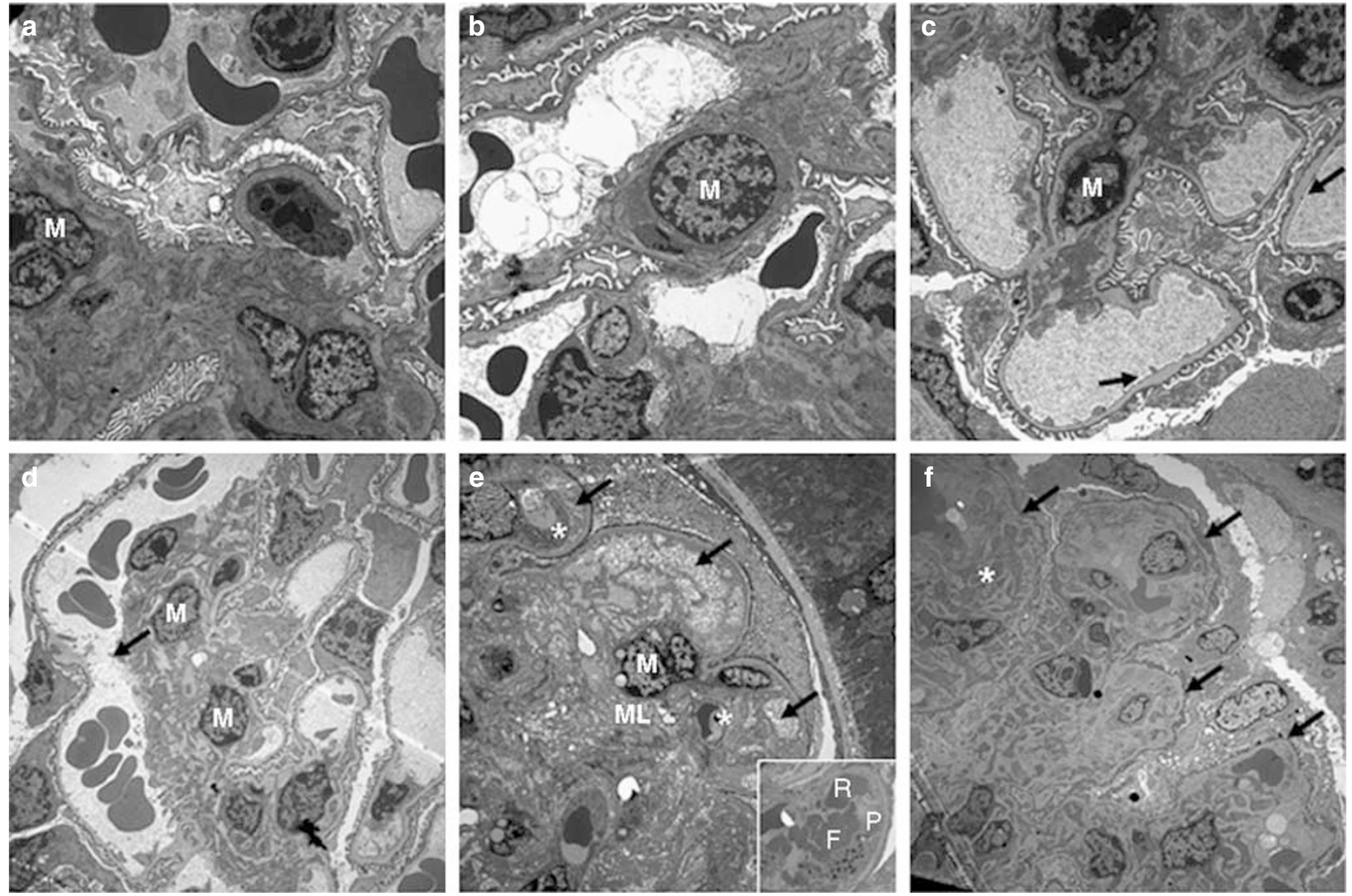

Figure 6 Electron microscopic analysis of lepr ${ }^{\mathrm{db} / \mathrm{db}}$, eNOS ${ }^{-1-}$ and DKO glomeruli at 16 weeks. (a) lepr ${ }^{\mathrm{db} / \mathrm{db}}$, (b) eNOS ${ }^{-1-}$ and (c) DKO glomeruli show mesangium (M) surrounded by capillaries. The mesangial matrix is prominent and the GBM is thickened in DKO mice compared to lepr $\mathrm{db}^{\mathrm{db} / \mathrm{db}}$ and eNOS ${ }^{-1}$ mice. (d-f) Ultrastructural features of injured glomeruli in DKO mice. (d) Microaneurysm with disruption of anchoring of GBM to mesangium (arrow). (e) Mesangiolysis and endothelial injury. Accumulation of electron-lucent material is present within the mesangium (ML) and extends into the subendothelial space of adjacent capillary walls (arrows). There is widespread endothelial injury with endothelial denudation from the basement membrane ${ }^{*}$ ). Some capillary lumens showed platelets $(\mathrm{P})$ along the endothelium, fibrillar fibrin tactoids $(\mathrm{F})$, red blood cells $(\mathrm{R})$ and red cell fragments (inset). (f) Early nodular glomerular expansion. There is accentuation of the lobular architecture (arrows) associated with early nodular matrix expansion (asterisk). Original magnification: $\times 6000$ in (a-c), (e inset), $\times 3000$ in (d-e) and $\times 2500$ in (f). 


\section{Glomerular macrophages and endothelial morphology}

Histologic preparations were further analyzed for macrophages and endothelial morphology. To detect macrophages, immunostains for CD68 were performed. A significant macrophage infiltrate was not detected in control or eNOS ${ }^{-1-}$ glomeruli. Compared to lepr ${ }^{\mathrm{db} / \mathrm{db}}$ glomeruli that have occasional macrophages, DKO glomeruli showed increased macrophages (Table 2, Figure 7a and b). Endothelial morphology was assessed by immunostaining for PECAM-1 and results correlated with EM findings. Controls showed intense staining of endothelial cells lining glomerular capillary loops, whereas DKO mice showed endothelial damage, with focal loss of PECAM-1 staining (Figure 7c and d). Macrophage influx and endothelial loss were identified mainly in glomeruli with mesangiolysis. To determine the cause of endothelial loss in DKO mice, apoptosis was analyzed by TUNEL staining. Cells showing nuclear condensation and fragmentation, a hallmark of apoptosis, were identified in DKO, but not in control, lepr $^{\mathrm{db} / \mathrm{db}}$ or eNOS ${ }^{-1-}$ glomeruli (Table 2, Figure 7e and f). The majority of TUNEL-positive staining was within the capillary lumina, consistent with previous studies suggesting that these cells are of endothelial origin. Proliferation of glomerular cells was assessed by PCNA immunostaining. Compared to WT glomeruli, some injured glomeruli in DKO mice showed increased PCNA-positive cells. A number of these cells were identified within capillary lumina and may represent endothelial cells (Figure $7 \mathrm{~g}$ and $\mathrm{h}$ ).

\section{Tubular and interstitial morphology}

In tubulointerstitial areas, control, lepr ${ }^{\mathrm{db} / \mathrm{db}}$ and $\mathrm{eNOS}^{-/-}$ mice showed no significant tubular damage, whereas DKO mice showed dramatic tubular injury (Figure 8a,b,d,e $v s \mathrm{c}$ and $\mathrm{f}$ ). The tubules were dilated, lined by flattened epithelium and contained proteinaceous casts with occasional sloughed necrotic epithelial cells. TUNEL analysis confirmed increased apoptotic epithelial cells and PCNA stains showed enhanced cell proliferation that likely contributed to tubular re-epithelialization (Table 2, Figure $8 \mathrm{c}$ and f). Occasional cortical scars containing increased collagen, hypoplastic and sclerotic glomeruli, and tubule remnants were identified in kidneys from both DKO and eNOS ${ }^{-1-}$ mice (Figure $8 \mathrm{~g}-\mathrm{i}$ ). The frequency and extent of cortical scars in these groups of mice were similar, whereas scars were not identified in control and lepr ${ }^{\mathrm{db} / \mathrm{db}}$ mice. Outside of scars in $\mathrm{eNOS}^{-1-}$ mice and in control and lepr ${ }^{\mathrm{db} / \mathrm{db}}$ mice, interstitial collagen was primarily restricted to the adventitia of blood vessels, whereas in DKO mice, the parenchyma outside of scars showed increased collagen in between tubules. DKO mice also showed increased CD68-positive macrophages in the interstitium compared to controls (Table 2 , Figure $8 \mathrm{j}-1$ ).

\section{DISCUSSION}

Deficient NO bioavailability precedes the development of several known complications of diabetes. ${ }^{19}$ Even though the

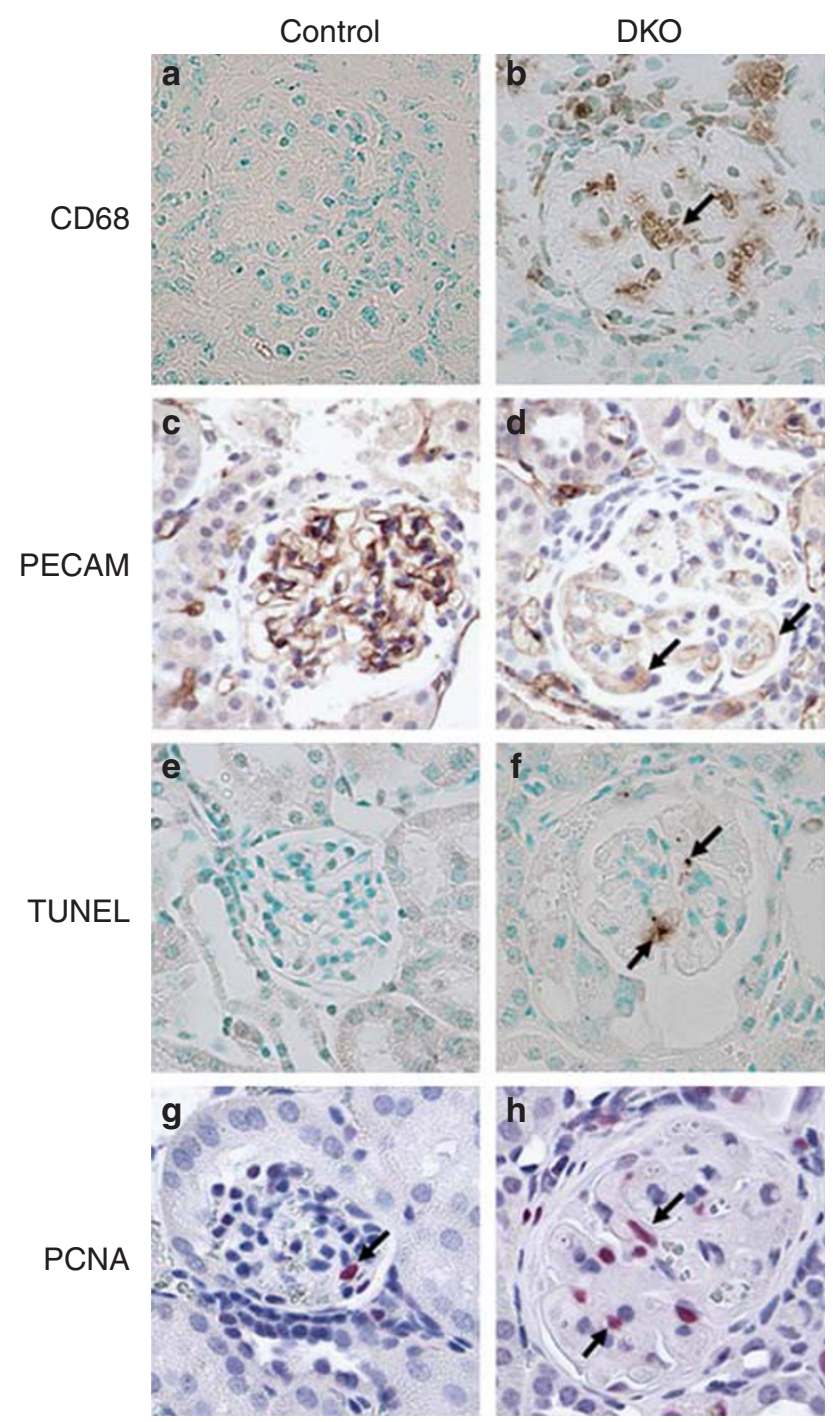

Figure 7 Detection of glomerular macrophages, endothelial cells, apoptosis and cell proliferation in WT and DKO mice. (a and $\mathbf{b}$ ) Immunostaining for CD68. Significant macrophage infiltration (brown color, arrow) is identified in DKO glomeruli but not in WT glomerulus. (c and d) Immunostaining for PECAM-1. Brown color indicates PECAM-1 staining as a marker of endothelial cells. WT glomerulus shows intact PECAM-1 staining along capillary walls. Injured glomerulus in DKO mouse shows endothelial loss associated with a decrease in PECAM-1 staining (arrows). (e and $\mathbf{f}$ ) TUNEL staining. Apoptosis is absent in WT glomeruli. TUNEL-positive apoptotic glomerular cells are identified in DKO glomerulus (arrows). The intracapillary location suggested that these cells were endothelial in origin. Note the marked condensation of nuclear chromatin and nuclear fragments that are classic markers of apoptosis. ( $\mathbf{g}$ and $\mathbf{h}$ ) Immunostaining for PCNA. Red color indicates proliferating cell. Compared to WT glomeruli, some injured glomeruli in DKO mice showed increased PCNA-positive cells, with some cells identified within capillary lumina (arrows). Original magnification: $\times 400$.

antiatherogenic and antioxidant attributes of eNOS have been widely recognized, the precise role of eNOS in individual organ systems that are exposed to the diabetic environment has not been explored. In the present study, we 

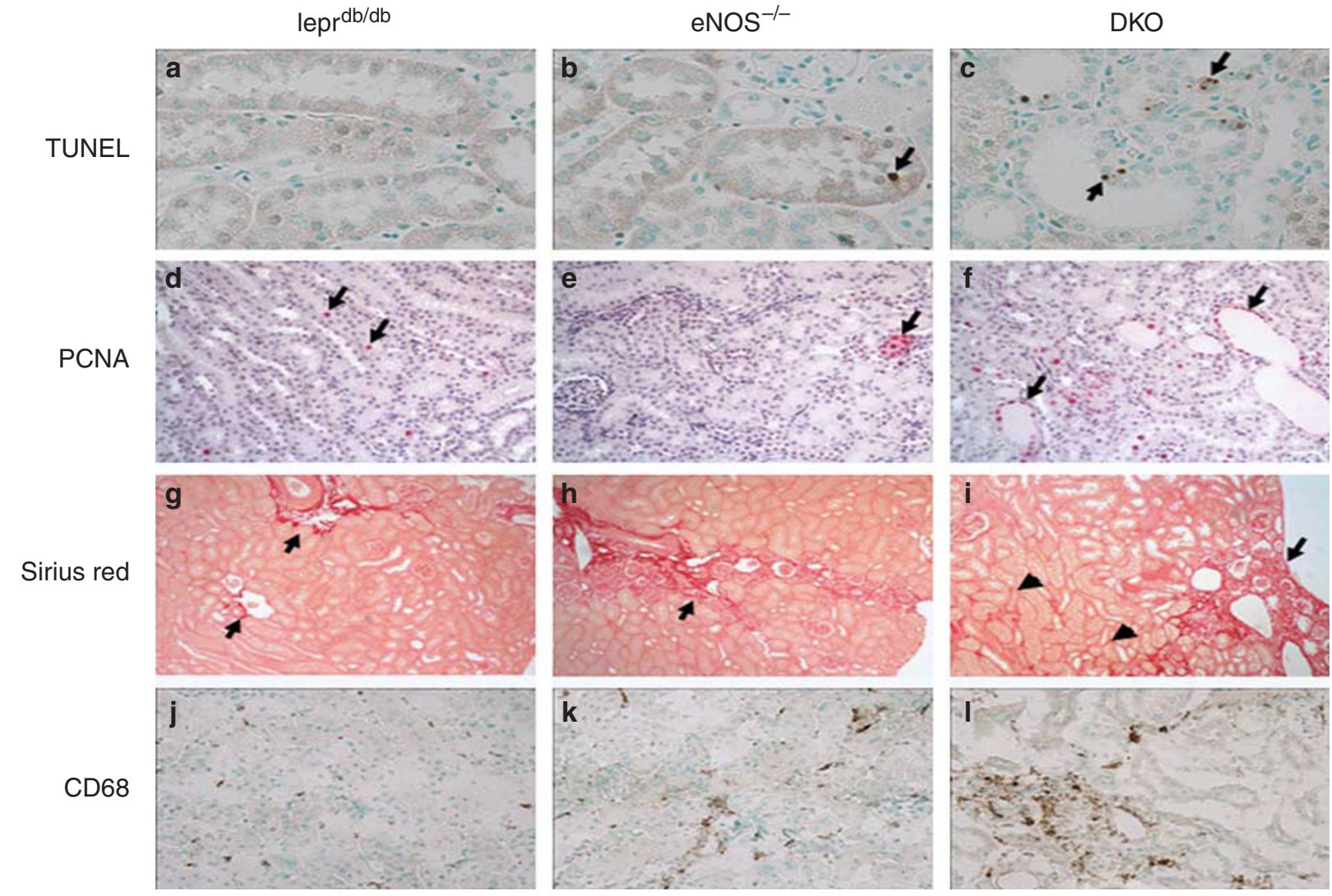

Figure 8 Detection of tubular epithelial-cell apoptosis and proliferation, interstitial fibrosis and macrophage infiltration. (a-c) TUNEL staining. Little or no apoptosis is identified in $\mathrm{db} / \mathrm{db}$ and eNOS-/- tubules. DKO mice show significant tubular injury (also shown in (f)) with tubular dilation, cast formation, flattened epithelium and increased apoptosis (arrows). (d-f) Immunostaining for PCNA. Compared to lepr ${ }^{\mathrm{db} / \mathrm{db}}$ and eNOS ${ }^{-/-}$, in DKO mice, injured tubules show increased epithelial-cell proliferation associated with re-epithelialization. (g-i) Picrosirius red staining. Collagen stains dark red. In lepr ${ }^{\mathrm{db} / \mathrm{db}}$ mice, interstitial collagen is restricted to adventitia of blood vessels (arrows). eNOS ${ }^{-1-}$ mice show increased collagen only within cortical scar (arrow), whereas in DKO mice, collagen is increased within scarred region (arrow) and in the adjacent parenchyma in between tubules (arrowheads). (j-I) Immunostaining for CD68. No significant macrophage infiltration is observed in the interstitium of lepr ${ }^{\mathrm{db} / \mathrm{db}}$ mice. Macrophages are increased in eNOS ${ }^{-1-}$ mice; however, macrophage infiltration is more prominent in the interstitium of DKO mice. Original magnification: $\times 400$ in $(\mathbf{a}-\mathbf{c}) ; \times 200$ in $(\mathbf{d}-\mathbf{f})$ and $(\mathbf{j}-\mathbf{l}) ; \times 100$ in $(\mathbf{g}-\mathbf{i})$.

generated DKO mice and show that they develop obesity, hyperglycemia, hyperinsulinemia and hypercholesterolemia. Surprisingly, accelerated atherosclerosis within the aorta was not observed, whereas significant glomerular capillary injury was identified. These findings provide the first evidence that eNOS mediates differential effects within the vascular system.

A salient feature of this DKO mouse is impaired re-endothelialization and remodeling within the aorta following injury. Vascular endothelial injury is an important risk factor for atherosclerosis and restenosis. To study the repair and remodeling processes, in previous studies, endothelial injury has been induced mechanically by (i) different diameters of angioplasty guide wire, ${ }^{20-23}$ (ii) spring wire, ${ }^{22}$ (iii) ligating the arteries using 9-0 nylon sutures, ${ }^{23}$ (iv) placing a cuff, ${ }^{24}(\mathrm{v})$ balloon distension, (vi) air desiccation and (vii) treatment with chemicals that selectively remove endothelial cells. However, shortcomings in most of these methods are unavoidable. For example, the use of air bubbles failed to remove endothelial cells completely at the region of interest, whereas, using chemicals, it was difficult to have control over the area of endothelial-cell denudation. ${ }^{25}$ Use of the mechanical guide wires and balloon distensions on the other hand could damage the media including the smooth muscle cells and elastin fibers beyond endothelium.

In the present study, we induced injury to the abdominal aorta by gently squeezing the aorta from the outside using a blunt-tip forceps. ${ }^{15}$ By adopting this method, we could achieve endothelial denudation in chosen area of the abdominal aorta more precisely without causing significant injury or damage to the medial wall. Our primary end point was to evaluate the extent of re-endothelialization in the injured vessels of eNOS ${ }^{-1-}$ mice on a diabetic setting. Results obtained using this method showed significantly higher medial wall thickness of both the injured $\mathrm{eNOS}^{-1-}$ and the DKO mice than the control and the lepr ${ }^{\mathrm{db} / \mathrm{db}}$ mice. The similar responses of remodeling observed in our model and in eNOS- I- mice analyzed using a carotid arterial ligation method ${ }^{26}$ clearly indicate that eNOS is an essential factor for vascular remodeling irrespective of the method of injury or the differences in vascular bed. Using a femoral artery injury 
procedure with an angioplasty guide wire, Stephenson $e t \mathrm{al}^{23}$ also reported an attenuated vascular response to arterial injury in lepr ${ }^{\mathrm{db} / \mathrm{db}}$ mice, which is in concordance with our results obtained from injury procedures we adopted. The average wall thickness of the injured vessel in lepr ${ }^{\mathrm{db} / \mathrm{db}}$ mice did not increase over that the control mice indicating the absence of remodeling response to arterial injury. Altered leptin signaling in lepr ${ }^{\mathrm{db} / \mathrm{db}}$ mice at the level of macrovessels has been implicated in the impaired responses to arterial injury. However, the increased wall thickness observed in the DKO mice indicated that depletion of eNOS has overridden the effect of altered leptin signaling. Proliferating smooth muscle cells could be responsible for this increased wall thickness. ${ }^{26}$ In our injury model, we have also provided direct evidence for the impaired re-endothelialization, which could be due to impaired migration of endothelial cells from adjacent uninjured regions into the denuded areas of the aorta or due to a decline in the rate of endothelial proliferation. It should be noted that the triply $\mathrm{NOS}^{-1-}$ knockout mouse model ${ }^{27}$ unlike the DKO model, presented with significant wall thickening and perivascular fibrosis in large epicardial coronary arteries and coronary microvessels in the absence of deliberate injury. This could be due to the depletion of all three isoforms of NOS, indicating the participation of other NOS isoforms in addition to eNOS in maintaining macrovascular health.

In addition to vasculopathy, DKO mice exhibited severe renal lesions that resemble human type II diabetic nephropathy. The significant increase in the ratios of urine albumin $v s$ creatinine levels strongly correlated with the progressive renal damage observed in these mice. Considering the development of extensive renal damage in these mice, it is compelling to speculate that hyperglycemia per se may not be the only factor responsible for the observed glomerular injury. In support of this, the plasma glucose levels of the DKO mice were infact significantly lower than those of the parent lepr ${ }^{\mathrm{db} / \mathrm{db}}$ strain. Therefore, it is logical to propose that the eNOS depletion associated with moderate hyperglycemia in DKO mice may rather be responsible for the severity of renal disease. Previous rodent models of diabetic renal disease have demonstrated mainly the early diabetic changes such as GBM thickening and mesangial expansion without significant nodular lesions. ${ }^{28}$ In DKO mice, nodular lesions appear as early as 8 weeks and progressive glomerular sclerosis is observed up to at least 40 weeks of age. These findings indicate that inactivation of eNOS exacerbates renal injury in diabetic lepr ${ }^{\mathrm{db} / \mathrm{db}}$ mice and provide direct evidence for a protective role of eNOS-derived NO in diabetic nephropathy.

Several mechanisms implicated in human diabetic nephropathy may account for the renal phenotype of DKO mice including hypertension, endothelial dysfunction, poor metabolic control and oxidative stress. The absence of eNOS in DKO mice is associated with systemic hypertension and arteriolar hyalinosis. This may contribute to the progressive diffuse glomerulosclerosis in DKO mice. DKO mice show a higher glomerular injury index compared to $\mathrm{NOS}^{-1-}$ mice. However, these groups of mice have comparable blood pressure levels, indicating that hypertension alone cannot account for the observed increase in renal injury in DKO mice. The spectrum of glomerular morphologies in DKO mice resembled the progressive stages observed in human type II diabetes where initially there is GBM thickening and mesangial expansion, followed by mesangiolysis that leads to microaneurysms and, with repeated microvascular injury, results in nodular lesions. Endothelial dysfunction and mesangiolysis occur in association with thrombotic microangiopathy and are thought to underlie the formation of microaneurysms and $\mathrm{K}-\mathrm{W}$ nodules in diabetes. This is supported by analysis of human $\mathrm{K}-\mathrm{W}$ nodules, which has shown RBC fragments in the mesangium and increased PAI-1 expression, a hallmark of microvascular injury associated with thrombotic microangiopathy. ${ }^{29}$

Hyperglycemia and eNOS deficiency-associated decreased NO generation may lead to endothelial damage. Previous studies indicate that endothelial cell-derived NO inhibits platelet aggregation, platelet and leukocyte adhesion to the endothelium and may have antithrombogenic and anti-inflammatory effects. ${ }^{9}$ The ability of eNOS-derived NO to prevent endothelial damage in diabetic nephropathy was demonstrated in $\mathrm{eNOS}^{-1-}$ mice injected with streptozotocin (STZ). These mice showed increased mesangiolysis and endothelial injury compared to wild-type diabetic controls and, with high dose of STZ, developed advanced diabetic nephropathy ${ }^{30,31}$ In diabetic lepr ${ }^{\mathrm{db} / \mathrm{db}}$ mice, deficiency of eNOS resulted in accelerated nephropathy with mesangiolysis and early nodular lesions at 26 weeks. ${ }^{32}$ However, in the later fasttrack report, limited to renal studies, the authors neither described endothelial injury, significant tubulointerstitial damage nor provided substantial quantitative analysis.

Our study provides the first evidence of impaired endothelial function in eNOS-deficient lepr ${ }^{\mathrm{db} / \mathrm{db}}$ mice, with glomeruli showing endothelial loss, intracapillary fibrin, platelets and monocytes. Moreover, absence of eNOS in DKO mice led to increased interstitial monocytes and acute tubular injury. It is tempting to speculate that hyperglycemia and eNOS deficiency act in concert to enhance reactive oxygen species production and, in the absence of NO generation, lead to persistent endothelial, tubular and interstitial damage. Clinically, some but not all patients develop diabetic nephropathy and our data suggest that endogenous availability of eNOS may be a key determinant for the development of nephropathy. Renal structural changes have been reported in triply NOS $-/-$ mice $;{ }^{27}$ however, in our model, the depletion of eNOS alone resulted in significant glomerular and tubulointerstitial injury suggesting that there is no appreciable compensation from other NOS isoforms.

The mechanism(s) by which chronic hyperglycemia associated with eNOS deficiency leads to greater detrimental effects in the glomerular microvasculature than in the larger aortic vessel remains to be determined. Macrovessels differ 
significantly from the glomerular capillary bed with respect to architecture and cellular components. The glomerular capillary wall is a filtration unit that consists of endothelial cells, basement membrane and podocytes whereas large vessels consist of endothelial cells and smooth muscle cells. Unlike large vessels, the glomerulus is situated between afferent and efferent arterioles that maintain intravascular pressure required for glomerular filtration. ${ }^{33,34}$ Taken together, multiple factors including the specific cell types and hemodynamics within the microenvironment likely contribute to the distinct effects observed in the macro- and microvessels.

In summary, DKO mice provide an optimal model for examining macro- and microvascular complications of diabetes. Further understanding of the mechanisms involved in initiating the renal lesions in DKO mice may suggest novel therapeutic strategies to prevent the onset and/or abrogate established diabetic nephropathy.

\section{ACKNOWLEDGEMENT}

This work was supported in part by National Institutes of Health (Grant no: 63032), Institutional ERC pilot project (118778) to SM; San Antonio Area

Foundation (Grant nos. 118981 to SM and 120909 to MN); National Institutes of Health (AR 42306) and VA Merit Award to SW; American Diabetes Association to NM.

1. Hink $\mathrm{U}, \mathrm{Li} \mathrm{H}, \mathrm{Mollnau} \mathrm{H}$, et al. Mechanisms underlying endothelial dysfunction in diabetes mellitus. Circ Res 2001;88:E14-E22.

2. Hoshiyana M, Li B, Yao J. Effect of high glucose on nitric oxide production and endothelial nitric oxide synthase protein expression in human glomerular endothelial cells. Nephron Exp Nephrol 2003;95:e62-e68.

3. Huang PL. Endothelial nitric oxide synthase and endothelial dysfunction. Curr Hypertens Rep 2003;5:473-480.

4. Deng A, Baylis C. Locally produced EDRF controls preglomerular resistance and ultrafiltration coefficient. Am J Physiol Renal Fluid Electrolyte Physiol 1993;264:F212-F215.

5. Zatz R, de Nucci G. Effects of acute nitric oxide inhibition on rat glomerular microcirculation. Am J Physiol Renal Fluid Electrolyte Physiol 1991;261:F360-F363.

6. Mattson DL, Roman RJ, Cowley AW. Role of nitric oxide in renal papillary blood flow and sodium excretion. Hypertension 2001;19: 766-769.

7. Komers R, Anderson S. Paradoxes of nitric oxide in the diabetic kidney. Am J Physiol Renal Physiol 2003;284:F1121-F1137.

8. Tolins JP, Shultz PJ, Raij L, et al. Abnormal renal hemodynamic response to reduced renal perfusion pressure in diabetic rats: role of NO. Am J Physiol Renal Fluid Electrolyte Physiol 1993;265:F886-F895.

9. Heeringa $\mathrm{P}$, Van Goor $\mathrm{H}$, Itoh-Lindrom $\mathrm{Y}$, et al. Lack of endothelial nitric oxide synthase aggravates murine accelerated anti-glomerular basement membrane glomerulonephritis. Am J Pathol 2000;156: 879-888.

10. Noyman I, Marikovsky M, Sasson S, et al. Hyperglycemia reduces nitric oxide synthase and glycogen synthase activity in endothelial cells. Nitric Oxide 2002;7:187-193.

11. Constentino F, Hishikawa K, Katusic ZS, et al. High glucose increases nitric oxide synthase expression and superoxide anion generation in human aortic cells. Circ Res 1997;96:25-28.

12. Ho FM, Liu SH, Liau CS, et al. Nitric oxide prevents apoptosis of human endothelial cells from high glucose exposure during early stage. J Cell Biochem 1999;75:258-263.
13. Lorenzi M, Cagliero E. Pathobiology of endothelial and other vascular cells in diabetes mellitus. Diabetes 1991;40:653-659.

14. Asaba K, Tojo A, Onozato ML, et al. Effects of NADPH oxidase inhibitor in diabetic nephropathy. Kidney Int 2005;67:1890-1898.

15. Reddick RL, Zhang SH, Maeda N. Aortic atherosclerotic plaque injury in apolipoprotein E deficient mice. Atherosclerosis 1998;140: 297-305.

16. Forbes MS, Thornhill RB, Park MH, et al. Lack of endothelial nitric-oxide synthase leads to progressive focal renal injury. Am J Pathol 2007;170:87-99.

17. Gavrieli $Y$, Sherman $Y$, Ben-Sasson SA. Identification of programmed cell death in situ via specific labeling of nuclear DNA fragmentation. J Cell Biol 1992;119:493-501.

18. Shesely EG, Maeda N, Kim H-S, et al. Elevated blood pressures in mice lacking endothelial nitric oxide synthase. Proc Natl Acad Sci USA 1996:93:13176-13181.

19. Erdely A, Freshour G, Maddox DA, et al. Renal disease in rats with type 2 diabetes is associated with decreased renal nitric oxide production. Diabetologia 2004;47:1672-1676.

20. Iwakura A, Luedemann C, Shastry S, et al. Estrogen-mediated, endothelial nitric oxide synthase-dependent mobilization of bone marrow-derived endothelial progenitor cells contributes to re-endothelialization after arterial injury. Circulation 2003;108: 3115-3121.

21. Hutter R, Sauter BV, Reis ED, et al. Decreased re-endothelialization and increased neointima formation with endostain overexpression in a mouse model of arterial injury. Circulation 2003;107:1658-1663.

22. Sata $M$, Maejima $Y$, Adachi F, et al. A mouse model of vascular injury that induces rapid onset of medial cell apoptosis followed by reproducible neointimal hyperplasia. J Mol Cell Cardiol 2000;32: 2097-2104.

23. Stephenson K, Tunstead J, Tsai A, et al. Neointimal formation after endovascular arterial injury is markedly attenuated in $\mathrm{db} / \mathrm{db}$ mice. Arterioscler Thromb Vasc Biol 2003;23:2027-2033.

24. Moroi M, Zhang L, Yasuda T, et al. Interaction of genetic deficiency of endothelial nitric oxide, gender, and pregnancy in vascular response to injury in mice. J Clin Invest 1998;101:1225-1232.

25. Lu X, Guo X, Linares $C$, et al. A new method to denude the endothelium without damage to media: structural, functional, and biomechanical validation. Am J Physiol Heart Circ Physiol 2004;286:H1889-H1894.

26. Rudic RD, Shesely EG, Maeda N, et al. Direct evidence for the importance of endothelium-derived nitric oxide in vascular remodeling. J Clin Invest 1998;101:731-736.

27. Tsutsui M, Shimokawa $H$, Morishita $T$, et al. Development of genetically engineered mice lacking all three nitric oxide synthases. J Pharmacol Sci 2006;102:147-154.

28. Sharma K, McCue $P$, Dunn SR. Diabetic kidney disease in the $\mathrm{db} / \mathrm{db}$ mouse. Am J Physiol Renal Physiol 2003;284:F1138-F1144.

29. Paueksakon $\mathrm{P}$, Revelo MP, Ma L-J, et al. Microagniopathic injury and augmented PAl-1 in human diabetic nephropathy. Kidney Int 2002;61:2142-2148.

30. Nakagawa T, Sato W, Glushakova O, et al. Diabetic endothelial nitric oxide synthase knockout mice develop advanced diabetic nephropathy. J Am Soc Nephrol 2007;18:539-550.

31. Kanetsuna $Y$, Takahashi $K$, Nagata $M$, et al. Deficiency of endothelial nitric-oxide synthase confers susceptibility to diabetic nephropathy in nephropathy-resistant inbred mice. Am J Pathol 2007;170: 1473-1484.

32. Zhao HJ, Wang $\mathrm{S}$, Cheng $\mathrm{H}$, et al. Endothelial nitric oxide synthase deficiency produces accelerated nephropathy in diabetic mice. J Am Soc Nephrol 2006;17:2664-2669.

33. Bonsib SM. Renal anatomy and histology. In: J Charles Jennette, Jean L. Olson, Melvin M. Schwartz and Fred G. Silva (eds). Heptinstall's Pathology of the Kidney, 6th edn. Lippincott Williams and Wilkins: Philadelphia, Pennsylvania, 2007, pp 1-70.

34. Elger M, Sakai T, Kriz W, et al. The vascular pole of the renal glomerulus of rat. Adv Anat Embryol Cell Biol 1998;139:1. 